\title{
Comparison of Success Rates and Complications of Midline and Paramedian Approaches of Spinal Anaesthesia
}

\author{
Aswathy Vijay V.S. ${ }^{1}$, Radhika K. ${ }^{2}$ \\ 1, 2 Department of Anaesthesiology, Sree Gokulam Medical College and Research Foundation, Kerala, India.
}

\section{ABSTRACT}

\section{BACKGROUND}

Neuraxial blockade has a wide range of clinical applications in the field of surgery, obstetrics and even pain management. The technique of spinal anaesthesia is simple and has high success rate and hence is most commonly performed in many institutions. It can be given in two approaches midline and paramedian but is associated with technical difficulties in elderly patients due to calcified interspinous ligaments. Hence, this study was conducted to compare the efficacies of both the approaches in elderly.

\section{METHODS}

160 patients of either sex above 50 yrs. of age belonging to ASA PS I-II posted for elective surgery under spinal anaesthesia were included in this observational study and were randomly divided into 2 groups of 80 in each group. M-SAB was done by midline approach group. P-SAB was done by paramedian approach. First attempt success rates were noted. Patients were followed up for 2 days postoperatively for signs of post dural puncture headache. Data was analysed with SPSS version 20.0.

\section{RESULTS}

Age, height and weight were compared between the two groups and the difference was found to be statistically insignificant. First attempt success rates were significantly higher in paramedian group (97.5\%) compared with midline (86.3\%) spinal. Incidence of PDPH (Post-Dural-Puncture Headache) was more in midline group $(6.3 \%)$ than paramedian group $(2.5 \%)$ but the result was statistically insignificant. Haemorrhagic tap was found in 5 out of 80 patients in midline group which was statistically significant. No paraesthesia or hematoma were noted. There were no complications.

\section{CONCLUSIONS}

Paramedian approach of lumbar puncture is superior to the conventional midline approach in elderly patients with regard to first attempt success rates and other complications.

\section{KEY WORDS}

Spinal Anaesthesia, Midline Approach, Paramedian Approach, Success Rates
Corresponding Author:

Aswathy Vijay V.S.

Sreesailam Tc 38/1981/1,

Aryasala Chalai Po, Trivandrum,

Kerala, India.

E-mail: aswathyvijay25@gmail.com

DOI: $10.14260 / \mathrm{jemds} / 2020 / 776$

How to Cite This Article:

Vijay AVS, Radhika K. Comparison of success rates and complications of midline and paramedian approaches of spinal anaesthesia. J Evolution Med Dent Sci 2020;9(47):3538-3542, $10.14260 /$ jemds $/ 2020 / 776$

Submission 26-03-2020,

Peer Review 08-10-2020

Acceptance 15-10-2020,

Published 23-11-2020.

Copyright (c) 2020 JEMDS. This is an open access article distributed under Creative Commons Attribution License [Attribution 4.0 International (CC BY 4.0)] 


\section{BACKGROUND}

Central neuraxial anaesthesia greatly expands the anaesthesiologists armamentarium providing the alternative to general anaesthesia. This technique by blunting the neuro endocrine stress response, reduces the incidence of major perioperative complications. Another importance of subarachnoid blockade is with a small volume of drug profound sympathetic, sensory and motor blockade necessary for surgery is very well obtained. This feature along with its high success rate and simplicity makes it the most commonly preferred regional anaesthetic technique. It can be given by either median or paramedian approach. ${ }^{1}$ For the midline approach, the desired interspace is palpated and local anaesthetic is injected into the skin and subcutaneous tissue. The spinal needle is introduced 10 - 15 degree cephalad. The needle traverses subcutaneous tissue, supraspinous ligament, interspinous ligament, ligamentum flavum, epidural space, dura mater, and subarachnoid mater and finally into the subarachnoid space. ${ }^{1}$ But in elderly patients this procedure carries significant technical difficulties due to calcified spinal ligaments and inability to adequately flex the spine, So a paramedian approach is used for spinal anaesthesia in such situatons. Here, first spinous process is palpated at the desired level. The needle is inserted $1 \mathrm{~cm}$ lateral to this point. Needle is then directed towards interspace medially and cephalad. The first resistance felt is usually ligamentum flavum and then a distinct pop when needle enters dura mater. ${ }^{2}$ Greater is the discomfort to the patient with increase in the number of attempts and also, more are complications like spinal haematoma, injury to the neural structures and PDPH. Hence, apt approach has to be followed in different scenarios. Midline approach of spinal anaesthesia is routinely practiced whereas paramedian approach is used only when midline approach fails. Hence, this study was conducted to compare the efficacy of midline and paramedian approach of spinal anaesthesia with regards to success rate, difficulties, advantage and complications in geriatric patients.

The aim of the study was to compare the midline and paramedian approaches of spinal anaesthesia with respect to success rates and complications in patients undergoing pelvic and lower limb surgeries

\section{Hypothesis}

Paramedian approach of spinal anaesthesia is better in elderly in reducing the number of attempts and complications.

\section{METHODS}

A prospective interventional study was conducted in Sree Gokulam Medical College and Research Foundation during 2016-17, 160 patients aged > 50 yrs. who were of physical status 1 and 2 according to ASA classification ${ }^{3}$ scheduled for pelvic or lower limb surgeries under spinal anaesthesia by either midline (group $\mathrm{Mn}=80$ ) or paramedian (group $\mathrm{P} n=$ 80) approach. Two groups were well matched with respect to age, height, weight, duration of surgery and gauge of the needle. Written informed consent was obtained from each patient after approving the study from Institutional Ethical
Committee. First attempt success rates, paraesthesia were noted. Patients were followed up for 3 days postoperatively for signs of post dural puncture headache.

\section{Inclusion Criteria}

- American Society of Anesthesiologist ASA1 and 11; patients of age $>50 \mathrm{yrs}$. undergoing pelvic and lower limb surgeries,

- Willing for spinal

- No existing neurological diseases

- No infection at the local site

- No coagulopathies

- Less than three attempts of SA (Spinal Anaesthesia)

- Without simultaneous GA (General Anaesthesia) administration

\section{Exclusion Criteria}

- More than three attempts of spinal

- History of migraine or headache preoperatively

\section{Sample Size}

From the article 'spinal anaesthesia with midline and paramedian technique in elderly patients' published in the Indian Journal of Applied Research vol 5 issue 9 September 2015.

Midline [p1] paramedian [p2].

Where, $p$-value of the success rates of two approaches

$\mathrm{p} 1$ (midline $)=68 \% \mathrm{p} 2($ paramedian $)=92 \%$

$\alpha=1 \%$

Power $(1-\beta)=90 \%$

Sample size,

$\mathrm{n}=\frac{[\mathrm{Z} 1-\alpha / 2 \sqrt{2} \mathrm{P}(1-\mathrm{P})+\mathrm{Z} 1-\beta \sqrt{\mathrm{p} 1}(1-\mathrm{p} 1)+\mathrm{p} 2(1-\mathrm{p} 2)] 2}{[\mathrm{P} 1-\mathrm{p} 2] 2}$

$\frac{\mathrm{P}=\mathrm{p} 1+\mathrm{p} 2}{2}$

Substituting in the above formula sample size equals 80 in each group.

\section{Study Variables}

Quantitative

Success rates, number of PDPH incidence.

Qualitative

Paraesthesiae, haemorrhagic tap.

\section{Outcome Measurements}

Success rates, PDPH incidence, first attempt success rates and other complications like paraesthesiae, haemorrhagic tap.

\section{Study Procedure}

After getting clearance from Institutional Research and Ethics Committee, patients were selected as per inclusion and 
exclusion criteria. Preoperative evaluation and relevant routine investigations were done. All patients kept nil per orally for $8 \mathrm{hrs}$. prior to surgery. Informed written consent for participation in the study were obtained from each patient. Patient data was recorded in the proforma. 30 mins prior to surgery all patients received $500 \mathrm{ml}$ Normal Saline (NS) intravenously (preloaded) and monitoring were done with Heart Rate (HR), NIBP (Non-Invasive Blood Pressure) , SpO2 peripheral capillary oxygen saturation , ECG (Electro-CardioGram). Approach of technique was blinded to patients, anesthesiologists who investigated patient outcomes and postoperative ward personnel. Under strict aseptic precautions, SA was given with 25G QB needle with either median or paramedian approach in RLDP (Right Lateral Decubitus Position) at L3-L4 space. If the midline approach is used, desired interspace is palpated. Local anaesthetic $2 \%$ lignocaine is injected into the skin and subcutaneous tissue. Then 25G QB needle is introduced which traverses the subcutaneous tissue, supraspinous ligament, interspinous ligament, ligamentum flavum, epidural space, dura mater, and subarachnoid mater and finally the subarachnoid space. If paramedian technique is used local anaesthetic is infiltrated 1 $\mathrm{cm}$ lateral to the inferior spinous process. The needle is then directed medially and cephalad which passes through subcutaneous fat, paraspinous muscle, ligamentum flavum, dura and finally subarachnoid space. Around $2.5-3.5 \mathrm{ml}$ of 0.5 $\%(\mathrm{H})$ bupivacaine was used according to type of surgery. The number of attempts, success rates, paraesthesiae, bloody tap were observed, and patients were followed from first postoperative day by another anaesthesiologist and were asked whether they were suffering from any problem concerning anaesthesia up to $3^{\text {rd }}$ day (PDPH).

\section{Statistical Analysis}

After collecting the data, it was entered in Microsoft Excel and analysed using SPSS software version 20. The necessary statistical tables were constructed along with charts and diagrams. Qualitative variables were expressed as percentages. Chi square and t test were used to compare the two groups wherever needed.

\section{RESULTS}

\section{Demographics}

Both groups were comparable in view of their age (Table 1), height (Table 2) and weight (Table 3).

\section{Comparison of Outcome Parameters \\ Success Rates}

Table shows that there were $100 \%$ success rates which means lumbar puncture was successfully accomplished in 160 cases through either of approaches with single or multiple attempts.

\section{First Attempt Success Rates}

- $\quad$ Single attempt for a successful Lumbar Puncture (LP) was performed in $97.5 \%$ of $\mathrm{P}$ group and $86.3 \%$ of $\mathrm{M}$ group

- Which shows there is a significant difference in the percentage of two groups.
- Chi-square analysis yielded a p value of 0.009 which is significant at 0.01 level.

\section{PDPH Incidence}

- $\quad 2.5 \%$ of study population complained of PDPH in P Group

- $6.3 \%$ of study population complained of PDPH in M Group

- Chi square was test of analysis

- Which shows a P value of 0.246 , which is $>$ than 0.05 hence statistically insignificant.

\section{Comparison of Complications}

None of the patients complained of any paraesthesia or haematoma in either of the group.

\begin{tabular}{|ccccc|}
\hline \multirow{2}{*}{ Age } & \multicolumn{2}{c}{ Paramedian } & \multicolumn{2}{c|}{ Midline } \\
& Count & Percent & Count & Percent \\
$51-60$ & 25 & 31.3 & 23 & 28.8 \\
$61-70$ & 38 & 47.5 & 30 & 37.5 \\
$>70$ & 17 & 21.3 & 27 & 33.8 \\
Mean \pm SD & \multicolumn{3}{c}{$64.9 \pm 6.2$} & \multicolumn{2}{c}{$66.9 \pm 8.1$} \\
\hline & Table 1. Age and Mode of Approach
\end{tabular}

Data was analysed by t-test and was found to yield a p value of 0.072 which is $>0.05$ Is no significant difference in the age between two patient groups

\begin{tabular}{|cccccc|}
\hline $\begin{array}{c}\text { Mode of Approach } \\
\text { Paramedian }\end{array}$ & Mean & SD & N & t & P \\
Midline & 162.9 & 6.9 & 80 & 0.38 & 0.704 \\
\hline \multicolumn{5}{c|}{ Table 2. Height and Mode of Approach } \\
\hline t test analysis of this data obtained a p value of 0.704 which shows groups were
\end{tabular}
comparable with regards to height distribution but statistically insignificant.

\begin{tabular}{|c|c|c|c|c|c|}
\hline Mode of Approach & Mean & SD & $\mathbf{N}$ & $\mathbf{t}$ & $\mathbf{P}$ \\
\hline Paramedian & 70.0 & 8.6 & 80 & \multirow{2}{*}{$2.49^{*}$} & \multirow{2}{*}{0.014} \\
\hline Midline & 66.1 & 10.8 & 80 & & \\
\hline \multicolumn{6}{|c|}{ Table 3. Weight and Mode of Approach } \\
\hline
\end{tabular}

\begin{tabular}{|c|c|c|c|c|c|c|}
\hline \multirow{2}{*}{ Success Rate } & \multicolumn{2}{|c|}{ Paramedian } & \multicolumn{2}{|c|}{ Midline } & \multirow{2}{*}{$\chi^{2}$} & \multirow{2}{*}{$\mathbf{P}$} \\
\hline & Count & Percent & Count & Percent & & \\
\hline Yes & 80 & 100.0 & 80 & 100.0 & \multirow{2}{*}{-} & 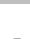 \\
\hline No & 0 & 0.0 & 0 & 0.0 & & - \\
\hline
\end{tabular}

Table shows that there were $100 \%$ success rates which means lumbar puncture was successfully accomplished in 160 cases through either of approaches with single or multiple attempts

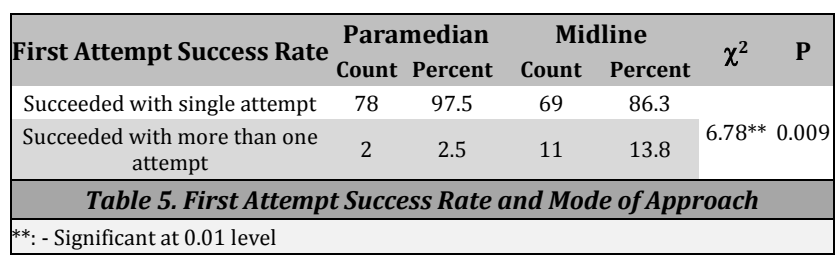

\begin{tabular}{|ccccccc|}
\hline $\begin{array}{c}\text { PDPH } \\
\text { Incidence }\end{array}$ & \multicolumn{3}{c}{ Paramedian } & \multicolumn{3}{c|}{ Midline } \\
Count & Percent & Count & Percent & $\chi^{2}$ & P \\
Yes & 2 & 2.5 & 5 & 6.3 & 1.34 & 0.246 \\
No & 78 & 97.5 & 75 & 93.8 & & \\
\hline \multicolumn{7}{c}{ Table 6. Incidence of PDPH and Mode of Approach } \\
\hline
\end{tabular}

\begin{tabular}{|cccccccc|}
\hline Paraesthesia / & \multicolumn{2}{c|}{ Paramedian } & \multicolumn{2}{c|}{ Midline } & \multirow{2}{*}{ P } & P \\
Haematoma & Count & Percent & Count & Percent & $\chi^{2}$ & \\
Yes & 0 & 0.0 & 0 & 0.0 & - & - \\
No & 80 & 100.0 & 80 & 100.0 & & \\
\hline Table 7. Paresthesia / Haematoma and Mode of Approach \\
\hline
\end{tabular}

\begin{tabular}{|ccccccc|}
\hline Haemorrhagic & \multicolumn{3}{c|}{ Paramedian } & \multicolumn{2}{c|}{ Midline } & \multirow{2}{*}{ P } \\
Tap & Count & Percent & Count & Percent & $\chi^{2}$ & \\
Yes & 2 & 2.5 & 5 & 6.3 & 1.34 & 0.246 \\
No & 78 & 97.5 & 75 & 93.8 & & \\
\hline \multicolumn{7}{|c}{ Table 8. Haemorrhagic Tap and Mode of Approach } \\
\hline
\end{tabular}




\section{DISCUSSION}

With regards to simplicity, appreciable success rates, lesser complications pre as well postoperatively, spinal anaesthesia is preferred to general anaesthesia for lower abdominal and lower limb surgeries and it is usually administered through midline approach. But when it comes to different scenarios like difficulty in flexing spine as in elderly, fractures, difficulty in palpating the spine as in obesity, paramedian approach is a better option to be attempted first. This approach which does not require flexed posture may be ideal in such situations as needle placement through para spinal muscle mass is easy. This approach offers several advantages over midline approach. ${ }^{4}$ With multiple attempts there are higher incidence of paraesthesia in patients with lumbar spine pathology. 5

The results of study revealed that there was a significant first attempt success rates, $12 \%$ more in paramedian group compared with midline approach of spinal anaesthesia.

PDPH incidence was about $4 \%$ more in midline approach than paramedian. Incidence of haemorrhagic tap was more in midline group compared to paramedian. No other clinically significant complications were observed.

Rabinowitz et al conducted a study on 40 elderly patients aged $>75$ yr. who underwent open surgical repair of a hip fracture under spinal, comparing both approaches and found that success rate was $85 \%$ in paramedian approach as compared to $45 \%$ in the median approach. ${ }^{6}$ Mericq o et al conducted a similar study and concluded that in patients who are elderly and with spinal deformity, paramedian approach is a safe alternative with higher success rate. ${ }^{7}$ Podder et al randomly allocated 50 patients scheduled for lower limb surgery after placing a lumbar epidural catheter in the sitting position with the back in unflexed position by either the midline or paramedian approach and concluded that with a patient sitting in neutral position, it is easier for insertion of needle in paramedian approach as compared to midline approach. ${ }^{8}$ Molina et al conducted a similar study comparing both techniques and found higher success rate with paramedian. ${ }^{9}$ Blomberg et al conducted study on 40 patients and found statistically significant difference between the two techniques in regard to repeated number of attempts and production of paresthesia. ${ }^{10}$ Leeda et al conducted study on 30 patients and found higher incidence of paraesthesia with midline approach. ${ }^{11}$ Our findings are again consistent with the above studies.

A study by Haider et al on 50 patients undergoing different elective surgeries under spinal anaesthesia found a statistically significant difference in the incidence of PDPH with the two approaches and concluded that the paramedian approach using the Quincke needle reduces the incidence of PDPH significantly. ${ }^{12}$ Paraesthesia was noted when the patient complained of a sharp pain in hips or legs while inserting the needle. In our study paraesthesia was not felt in the patients in either group.

Vascular trauma can be a complication of spinal anaesthesia. Epidural vessels are situated laterally. So, midline approach provides a relatively avascular plane. On the other hand, paramedian approach may encounter vessels leading to bloody tap. In our study the incidence of haemorrhagic tap in the paramedian group was $2.5 \%$ which is comparable with other studies.

\section{Limitations}

The main limitations of the study were small study population and short periods of follow up. Gender as a medium of comparison for PDPH incidence was not done which could have altered the results. A large study population could have yielded more significant results.

\section{Summary}

The study was an observational study to compare the midline and paramedian approaches of spinal anaesthesia with respect to success rates and complications in patients undergoing pelvic and lower limb surgeries. It was seen that first attempt success rates were more with paramedian approach to midline approach. With paramedian approach PDPH incidence and haemorrhagic taps were less. No other clinically significant complications were observed in either of the approaches.

\section{CONCLUSIONS}

Paramedian approach of lumbar puncture is superior to the conventional midline approach in elderly patients with regard to first attempt success rates and other complications.

Data sharing statement provided by the authors is available with the full text of this article at jemds.com.

Financial or other competing interests: None.

Disclosure forms provided by the authors are available with the full text of this article at jemds.com.

\section{REFERENCES}

[1] Muranaka K, Mizutani H, Seo K, et al. A comparison between midline and paramedian approaches for combined spinal-epidural anaesthesia. Masui 2001;50(10):1085-8.

[2] de Filho GRO, Gomes HP, da Fonseca MHZ, et al. Predictors of successful neuraxial block: a prospective study. Eur J Anaesthesiol 2002;19(6):447-51.

[3] Abouleish AE, Leib ML, Cohen NH. ASA provides examples to each ASA physical status class. ASA Monitor 2015;79:38-49.

[4] Janik R, Dick W. Post spinal headache. Its incidence following the median and paramedian technique. Anaesthetist 1992;41(3):137-41.

[5] Abizanda FP, Reina MA, Ruiz IF, et al. Paresthesia in various spinal anaesthesia techniques for cesarean section. Rev Esp Anestesiol Reanim 2007;54(9):529-36.

[6] Rabinowitz A, Bourdet B, Minville V, et al. The paramedian technique: a superior initial approach to continuous spinal anaesthesia in elderly. Anesth Analg 2007;105(6):1855-7.

[7] Mericq 0, Colombani A, Eychenne B, et al. Paramedian lumbar puncture for spinal anaesthesia in the elderly. Cah Anesthesiol 1985;33(8):685-7.

[8] Podder S, Kumar N, Yaddanapudi LN, et al. Paramedian lumbar epidural catheter insertion with patients in the sitting position is equally successful in the flexed and unflexed spine. Anesth Analg 2004;99(6):1829-32. 
[9] Molina A, Fons J. Factors associated with lumbar puncture success. Pediatrics 2006;118(2):842-4.

[10] Blomberg RG, Jaanivald A, Walther S. Advantages of paramedian approach for lumbar epidural analgesia with catheter technique. A clinical comparison between midline and paramedian approaches. Anaesthesia 1989;44(9):742-6.
[11] Leeda M, Stienstra R, Arbous MS, et al. Lumbar epidural catheter insertion: the midline vs. the paramedian approach. Eur J Anaesthesiol 2005;22(11):839-42.

[12] Haider S, Butt KJ, Aziz MA, et al. Post dural puncture headache-a comparison of midline and paramedian approaches. Biomedica 2005;21:90-2. 